\title{
PRODUKTIVITAS SUBSEKTOR INDUSTRI MAKANAN, MINUMAN DAN TEMBAKAU PROVINSI JAWA BARAT
}

\author{
Juri Juswadi \\ Fakultas Pertanian Universitas Wiralodra, Jln. Ir. H. Juanda Km 3, Indramayu, Indonesia, \\ jurijuswadi@unwir.ac.id
}

Diterima 20 Agustus 2019, disetujui 21 September 2019, diterbitkan 31 Oktober 2019

Pengutipan: Juswadi, J. (2019). Produktivitas Subsektor Industri Makanan, Minuman dan Tembakau Provinsi Jawa Barat. Gema Wiralodra, Vol 10, No 2, Hal 263-280, Oktober 2019

\begin{abstract}
ABSTRAK
Penelitian ini bertujuan untuk mengetahui produktivitas subsektor makanan, minuman, dan tembakau Provinsi Jawa Barat menggunakan analisis Total Factor Productivity (TFP). Produktivitas subsektor tersebut berperan penting dalam peningkatan pertumbuhan ekeonomi. Hasil penelitian menunjukkan bahwa Nilai TFP rata-rata subsektor makanan, minuman, dan tembakau Provinsi Jawa Barat selama periode 2002-2013 adalah 2,751, yang menunjukkan produktivitas dan efisiensi yang tinggi dari industri tersebut. Tetapi selama periode tersebut terjadi fluktuasi yang sangat besar yang diduga terutama disebabkan oleh fluktuasi pertumbuhan tenaga kerja pada tahun 2002, 2004, 2005, 2007, 2008, dan 2009.

Kata kunci: Produktivitas, Total Factor Produktivitas, subsektor makanan, minuman, dan tembakau
\end{abstract}

\section{ABSTRACT}

This study aims is to determine the productivity of the food, beverage, and tobacco subsector of West Java Province using Total Factor Productivity (TFP) analysis. The productivity of the subsector plays an important role in increasing economic growth. The results showed that the average TFP value of the food, beverage and tobacco subsector of West Java Province during the period 2002-2013 was 2.751, which shows the high productivity and efficiency of the industry. But during this period there were very large fluctuations which were thought to be mainly due to fluctuations in labor growth in 2002, 2004, 2005, 2007, 2008, and 2009

Keyword: Productivity, Total Factor Productivity, food, beverage, and tobacco subsector

\section{PENDAHULUAN}

Produktivitas secara sederhana dapat diartikan sebgai perbandingan antara output yang dihasilkan terhadap input yang digunakan dalam suatu proses produksi. Semakin tingi output yang dihasilkan dan semakin rendah input yang digunakan maka produktivitas akan semakin tinggi. Produktivitas merupan parameter yang sangat penting yang menggambarkan kemajuan suatu perusahaan dalam lavel mikro maupun suatu bangsa dalam lavel makro. Negara yang memiliki produktivitas tinggi dalam produksi sektor 
sektor ekonominya akan memiliki pendapatan nasional yang tinggi sehingga akan mensejahterakan bangsanya.

Menurut Saikia (2014) terdapat dua konsep produktivitas, yaitu. produktivitas parsial dan produktivitas faktor total. Produktivitas parsial mengukur kontribusi dari satu faktor (katakanlah tenaga kerja atau modal) terhadap pertumbuhan output dengan menjaga faktor-faktor lainnya tetap konstan. Karena itu terdapat konsep produktivitas tenaga kerja dan produktivitas modal, yang menggambarkan efisiensi penggunaan sumber daya. Produktivitas parsial tidak benar-benar mencerminkan apakah pertumbuhan produktivitas disebabkan karena lebih banyak menggunakan input atau terdapat peningkatan dalam efisiensi penggunaannya, maupun adanya peningkatan teknologi. Selain itu produktivitas parsial juga mengabaikan waktu, produk sekunder, input selain lahan, tenaga kerja, modal, dan eksternalitas. Oleh karena itu terdapat konsep total faktor produktivitas (Total Factor Productivity) yang disngkat dengan TFP. TFP mengukur pertumbuhan bersih output per unit dari total input. Dengan demikian, levelnya ditentukan oleh seberapa efisien dan intens input digunakan dalam produksi. TFP dianggap sebagai ukuran produktivitas yang lebih akurat dibandingkan dengan produktivitas parsial.

Menurut Miller dan Meiner (2000), sumber daya atau faktor produksi atau input dapat dikelompokkan menjadi sumber daya manusia (termasuk tenaga kerja dan kemampuan manajerial/enterpreneurship), modal (capital), dan tanah atau sumber daya alam. Kemamapuan manajerial adalah kemampuan yang dimiliki individu dalam melihat berbagai kemungkinan untuk mengkombinasikan sumber daya guna menghasilkan dengan cara baru atau cara yang lebih efisien, baik produk baru maupun produk yang sudah ada. Namun untuk menyederhanakan pembahasan, faktor produksi tersebut dapat dikelompokkan menjadi dua kategori, yaitu: tenaga kerja (labor) dan modal (capital). Klasifikasi itu bisa diubah-ubah sesuai dengan kadar analisis yang dibutuhkan. Klasifikasi lebih jauh terbagi menjadi dua golongan input, yaitu input tetap (fixed input) dan input yang berubah-ubah atau input variabel (variable input). Input tetap adalah input yang tidak dapat diubah jumlahnya dalam waktu tertentu atau bisa diubah namun dengan biaya sangat besar. Input variabel adalah input yang dapat diubah dengan cepat dalam jangka pendek 
Biasanya kalau klasifikasi ini yang dipakai maka untuk menyederhanakan pembahasan, modal dianggap (diasumsikan) sebagai input tetap dan tenaga kerja sebagai input variabel.

Pengamatan Shanmugan dkk (2018) menunjukan bahwa Analisis TFP tidak hanya membantu memahami logika makroekonomi melalui pengamatan variasi dalam output pertanian, tetapi juga memotivasi pemahaman tentang masalah yang berkaitan dengan pertanian tersebut karena risiko produksi pertanian, profitabilitas, tingkat pengembalian pada investasi pertanian, dinamika pasar tenaga kerja pertanian dan proses penentuan tingkat upah pada berbagai struktur pasar. Selain itu juga penting dalam implementasi kebijakan dan intervensi Pemerintah untuk mencapai kondisi pembangunan sektor pertanian yang stabil .

Menurut Sukirno (2002), fungsi produksi adalah hubungan antara faktor-faktor produksi (input) dengan tingkat produksi (output) yang diciptakannya. Di dalam teori ekonomi, di dalam menganalisis mengenai produksi, selalu dimisalkan bahwa faktor produksi tanah dan modal adalah tetap jumlahnya. Hanya tenaga kerja yang dipandang sebagai faktor produksi yang berubah-ubah jumlahnya. Dengan demikian, di dalam menggambarkan hubungan di antara faktor produksi yang digunakan dan tingkat produksi yang dicapai, yang digambarkan adalah hubungan di antara jumlah tenaga kerja yang digunakan dan jumlah produksi yang dicapai. Fungsi produksi dapat dinyatakan sebagai: $\mathrm{Q}=\mathrm{f}(\mathrm{K}, \mathrm{L}$,$) . Notasi \mathrm{K}$ adalah jumlah stok modal, $\mathrm{L}$ adalah jumlah tenaga kerja, sedangkan $\mathrm{Q}$ adalah jumlah produk yang dihasilkan.

Produktivitas dalam pertanian dapat dihitung sebagai produktivitas parsial yang merujuk pada satu faktor tunggal atau total produktivitas (multi-faktor). Indeks TFP adalah hubungan dari total produksi dengan total pengeluaran untuk produksi tersebut (Coelli dkk. 2005 dalam Kijek dkk, 2019). Penerapan indeks TFP dalam analisis ekonomi dikaitkan dengan sifat komprehensif yang dihasilkan dari agregat pengeluaran. Menurut Juarno dkk (2011) dalam hasil penelitiannya, arti angka indeks TFP secara individu adalah: untuk tiap petakan dalam studi mencerminkan perbedaan produktivitas dibandingkan nilai rata-rata setiap petakan. Petakan tambak yang mempunyai nilai 1.37 artinya mempunyai TFP $37 \%$ lebih tinggi dibandingkan rata-rata. 
Pentingnya teknologi dalam peningkatan produktitas dinyatakan Lipsey dan Carlaw (2004) bahwa technological knowledge terkait erat dengan proses penciptaan nilai ekonomi. Lipsey menjelaskan bahwa technical progress yang terjadi tidak hanya dalam bentuk alih teknologi yang terjadi saja melainkan juga mencakup perubahan-perubahan lainnya yang terjadi pada seluruh faktor input yang sebenarnya digunakan dalam suatu proses produksi namun tidak dimasukkan dalam perhitungan untuk mengetahui efeknya terhadap perubahan output yang terjadi. Penguasaan teknologi dalam suatu proses produksi meskipun tidak selalu mutlak diperlukan namun tak bisa dipungkiri dapat membantu dalam peningkatan produktivitas. Oleh karena itu, pertumbuhan output tidak harus selalu disebabkan adanya perubahan dalam intensitas pemakaian faktor produksi (input) namun bisa juga dipengaruhi oleh perubahan dalam produktivitasnya yang salah satunya ditunjukkan dengan seberapa besar technical progress yang terjadi dalam perusahaan maupun secara keseluruhan dalam tingkat industri. Perhitungan untuk mengetahui seberapa besar tingkat produktivitas itu sendiri dapat dilakukan melalui beberapa cara diantaranya melalui pengukuran produktivitas secara parsial maupun secara total.

Pertumbuhan ekonomi ditentukan oleh jumlah tenaga kerja, modal yang tersedia, dan penguasaan teknologi yang akan menghasilkan produktivitas yang tinggi. Penguasaan teknologi akan meningkatkan produktivitas sehingga produksi nasional pada berbagai sektor ekonomi akan meningkat. Menurut Asian Produkivity Organizatio, (2004) pertumbuhan ekonomi yang didasarkan pada pertumbuhan produktivitas, yaitu produktivitas total yang seimbang antara pertumbuhan investasi modal dan pertumbuhan SDM (human capital/ knowledge) akan menghindarkan dari pertumbuhan ekonomi yang semu. Apabila membandingkan pertumbuhan GDP dari tahun 1980-2000 dengan pertumbuhan produktivitas pada negara-negara Asean seperti ditunjukkan dalam Tabel 1. Malaysia, Thailand, dan Vietnam merupakan contoh suatu pertumbuhan ekonomi yang didasarkan pada pertumbuhan TPF (modal dan tenaga kerja). Pertumbuhan ekonomi secara efisien (produktif) menjadi modal dasar bagi persaingan regional dan global. 
Tabel 1. Nilai Total Faktor Produkivity (TFP) Negara ASEAN Periode 1980-2000

\begin{tabular}{lllllc}
\hline Negara & $1980-1984$ & $1985-1989$ & $1990-1994$ & $1995-1999$ & $1980-2000$ \\
\hline Indonesia & $-0,32$ & 0,47 & $-0,82$ & $-3,67$ & $-0,80$ \\
Malaysia & 0,74 & 0,20 & 3,36 & 0,32 & 1,29 \\
Philipina & $-2,34$ & 0,49 & $-1,68$ & 1,03 & $-0,37$ \\
Singapura & $-0,20$ & 1,25 & 2,33 & $-0,41$ & 0,78 \\
Thailand & 0,37 & 3,66 & 2,14 & -2.16 & 1,00 \\
Vietnam & - & 2,02 & 4,12 & 3,22 & 3,27 \\
\hline
\end{tabular}

Sumber: Asian Produkivity Organization, 2004

Potensi sektor industri pertanian domestik harus diikuti dengan peningkatan produktivitas agar perkembangan output industri pertanian dapat terus ditingkatkan dengan penggunaan faktor-faktor produksi yang optimal dan didukung efisiensi produksi, seperti peningkatan teknologi dan input pada sektor industri pertanian. Industri pertanian yang berperan sebagai alat pertumbuhan ekonomi nasional seharusnya dapat meningkatkan output-nya secara berkelanjutan dengan tingat efisiensi yang tinggi (Mayashinta dan Firdaus, 2013).

Hasil penelitian Jabir (2009) menunjukkan bahwa pengolahan makanan di India memiliki potensi besar dalam pendapatan dan lapangan pekerjaan melalui nilai tambah karena ketersediaan sumber daya, tenaga kerja, teknologi, pasar besar dan lingkungan bisnis yang menguntungkan. Tingkat pengolahan makanan di negara ini masih dalam tahap awal dan hanya sedikit hasil pertanian diproses. Pertumbuhan industri pengolahan makanan India terutama terkendala karena kurangnya teknologi yang menambah produktivitas dan pemanfaatan sumber daya yang terbatas. Karena itu, teknologi adalah kunci untuk meningkatkan pertumbuhan dan efisiensi di sektor pengolahan. Selanjutnya dinyatakan bahwa Variabilitas dalam efisiensi dan nilai TFP pada sektor industri pengolahan makanan menunjukkan bahwa nilai tambah yang tinggi pada produk permen, daging, buah-buahan dan sayuran. Hal ini berarti terdapat perubahan struktural di sektor pengolahan makanan menuju sektor bernilai tinggi mengikuti perubahan pola konsumsi di pasar domestik. Hal ini menunjukkan bahwa sektor industri pengolahan makanan dengan nilai tambah yang tinggi memiliki peluang lebih besar dalam daya tarik investasi. 
Menurut (Depnakertrans, 2003), subsektor industri pengolahan merupakan sektor terpenting dalam ekonomi nasional dan bersifat sangat dinamis. Linkages dengan sektor lain sangat besar dan luas. Pertumbuhannya dapat mendorong dan menarik pertumbuhan sektor lainnya karena sektor industri memerlukan input dari dan outputnya banyak dipakai oleh sektor lain. Karena itu sering dipercaya merupakan mesin pertumbuhan nasional. Perkembangan sektor industri pengolahan merupakan yang tercepat dibandingkan dengan sektor-sektor lain dan telah dapat menyediakan kesempatan kerja yang sangat berarti dan produktif. Lain halnya dengan sektor lain seperti jasa-jasa dan pertanian yang banyak menampung tenaga kerja informal yang kurang produktif.

Industri makanan, minuman, dan tembakau merupakan salah satu subsektor dalam sektor industri pengolahan yang penting dalam perekonomian Indonesia karena memiliki keterkaitan ke belakang yang kuat dengan sektor pertanian, demikian pula memiliki keterkaitan ke depan dengan sektor industri lainnya maupun dengan sektor perdagangan. Produktivitas yang tinggi dari subsektor ini akan mendorong peningkatan produksi sektor lainnya. Sektor ini juga berperan penting dalam memberikan kontribusi pada pendapatan domestik regional bruto (PDRB) pada wilayah Provinsi maupun secara nasional. Juga memberikan peluang yang sangat luas bagi teransformasi tenaga kerja sektor pertanian ke sektor industri pengolahan, melalui usaha mikro, kecil, dan menengah (UMKM). Subsektor makanan, minuman, dan tembakau merupakan subsektor yang sangat berkembang dan tumbuh dengan output yang tinggi diantara subsektor industri pengolahan lainnya, serta merupakan subsektor yang sangat penting dalam penyediaan pangan di Jawa Barat. Kontribusi subsektor industri pengolahan terhadap PDRB Provinsi Jawa Barat periode 2007-2010 (atas dasar harga konstan 2000) dapat dilihat pada Lampiran 1.

Penelitian terdahulu tentang produktivitas industri hasil pertanian Indonesia telah dilakukan anatara lain oleh Mayashinta dan Firdaus (2013) yang bertujuan untuk 1) menganalisis total factor productivity (TFP) industri pertanian di Indonesia melalui dengan pendekatan fungsi produksi cobb-douglas dan 2) untuk menganalisis faktor-faktor yang memengaruhi TFP industri pertanian menggunakan metode error correction model (ECM).Metode yang digunakan adalah metode kuantitatif untuk mengukur tingkat TFP 
yaitu metode ordinary least square dan faktor-faktor yang memengaruhi TFP dengan menggunakan metode ECM. Hasil penelitiannya antara lain: nilai pertumbuhan TFP industri pertanian tahun 1981-2010 menunjukkan bahwa tingkat produktivitas industri pertanian masih lemah. Hal ini ditunjukkan oleh besaran nilai TFP industri pertanian yang bernilai negatif baik itu saat sebelum krisis maupun setelah krisis. Hasil TFP pada industri pertanian sebelum krisis merepresentasikan nilai yang lebih rendah dibandingkan dengan pertumbuhan TFP pada periode setelah krisis. Hal ini menandakan terjadinya perkembangan teknologi dalam industri pertanian setelah terjadinya krisis tahun 1997 1998.

Hasil analisis TFP subsektor yang memiliki efisiensi tertinggi dalam penggunaan faktor produksinya adalah industri makanan, minuman, dan tembakau. Hal ini dikarenakan subsektor tersebut merupakan industri yang padat modal, tenaga kerja yang tinggi, dan penyerapan teknologi cenderung tinggi. Subsektor yang memiliki nilai TFP terendah adalah industri kayu dan anyaman. Hal ini disebabkan oleh penyerapan teknologi pada industri kayu masih lemah dan faktor produksi cenderung lebih tinggi pada tenaga kerja dibandingkan dengan penggunaan mesin (Mayashinta dan Firdaus, 2013).

Penelitian lainnya dilakukan oleh Juarno dkk (2011) pada produktivitas tambak udang bertujuan untuk menganalisis kinerja produktivitas tambak udang dan mengetahui faktor-faktor yang mempengaruhi TFP menggunakan pendekatan angka Indeks Tornqvist Theil. Hasil studi menunjukkan bahwa pertumbuhan udang tambak Indonesia periode 1989-2008 lebih karena pertumbuhan input/faktor produksi bukan karena pertumbuhan TFP. TFP berfluktuasi disebabkan belum berhasil diatasinya permasalahan penyakit. Hasil konfirmasi pada tingkat lapang menggunakan data primer dari 163 petak tambak menunjukkan bahwa serangan penyakit berpengaruh negatif dan signifikan terhadap TFP. Intensifikasi, benur bersertifkat, dan lamanya pendidikan berkorelasi positif, akan tetapi kondisi riil Indonesia berbeda yaitu mayoritas tambak dikelola secara non intensif. Studi ini juga menunjukkan bahwa luas pengusahaan dan sistem kerjasama antara pembudidaya dengan lembaga pemasaran lainnya berpengaruh negatif terhadap TFP 
Penenelitian penelitian penulis berbeda dengan penelitian sebelumya dalam hal hanya mengidentifikasi produktivitas pada subsektor makanan, minuman,dan tembakau di Provinsi Jawa Barat, pada tahun 2001 sampai dengan tahun 2013. Penelitian ini berlandaskan pada peningkatan output subsektor makanan, minuman, dan tembakau penting diketahui dalam upaya meningkatkan produktifitasnya agar output yang dihasilkan semakin tinggi, dengan biaya yang lebih efisien. Output proses produksi suatu produk dengan input yang sama seringkali berbeda mengingat terdapat faktor lain yang menyebabkan perbedaan tersebut. Faktor tersebut berkaitan dengan penguasaan teknologi, menajemen, keterampilan tenaga kerja dan lainnya dalam memproduksi produk tersebut yang tidak tidak dijelaskan dalam fungsi produksi. Berdasarkan latar belakang ini penulis tertarik untuk melakukan penelitian dengan judul: Produktivitas Subsektor Industri Makanan, Minuman dan Tembakau Provinsi Jawa Barat. Tujuan penelitian ini adalah untuk mengidentifikasi indeks TFP subsektor makanan, minuman, dan tembakau Provinsi Jawa Barat pada periode 2001-2013. Hasil Penelitian ini diharapkan sebagai referensi bagi para pengambil kebijakan dalam meningkatkan pertumbuhan dan kontribusi subsektor tersebut dalam PDRB Jawa Barat.

\section{METODOLOGI PENELITIAN}

Obyek penelitian ini adalah keadaan produksi `subsektor makanan, minuman, dan tembakau di Provinsi Jawa Barat pada tahun 2000-2013. Metode penelitian ini adalah metode deskriptik yang bertujuan menguraikan nilai TFP subsektor makanan, minuman Provinsi, dan tembakau Provinsi Jawa Barat. Operasionalisaisi Variabel dalam penelitian ini adalah:

1. Total Faktor Produktivitas (TFP), adalah: sisa pertumbuhan output setelah dikurangi dengan pertumbuhan input-inputnya, dinilai dengan satuan persentase;

2. Produksi subsektor industri makanan, minuma, dan tembakau (OUT), adalah: Output yang dihasilkan oleh subsektor tersebut sebagai industri pengolahan yang berbasis produk pertanian primer dengan skala usaha besar menengah dan kecil di Provinsi Jawa Barat yang dinilai dengan satuan rupiah; 
3. Tenaga Kerja (TK), adalah: banyaknya jumlah tenaga kerja yang digunakan pada subsektor agroindustri makanan dan minuman Provinsi Jawa Barat yang dinilai dengan jumlah orang;

4. Biaya Input (IN), adalah biaya pembelian barang - barang input baik barang mentah maupun barang setengah jadi yang digunakan dalam proses produksi agrtoindustri maknan dan minuman selain dari modal, tenaga kerja dan energi di Provinsi awa Barat. Bahan baku dinilai dengan satuan rupiah.

5. Energi (EN), adalah penjumlahan dari energi yang dipakai dalam agroindustri makanan dan minuman di Provinsi Jawa Barat, yaitu bahan bakar dan listrik, dinilai dengan satuan rupiah;

Data dalam penelitian ini adalah data sekunder yang diterbitkan oleh Badan Pusat Statistik Provinsi Jawa Barat, Laporan Tahunan Dinas Perindustrian Provinsi Jawa Barat, instansi lainnya. Penelitian ini menggunakan metode deskriptif melalui analisis kuantitatif. Metode deskriptif adalah memberikan gambaran dari hasil penelitian, sedangkan analisis kuantitatif digunakan untuk melihat pengaruh variabel-variabel yang saling berhubungan. Metode kuantitatif yang digunakan untuk mengukur tingkat TFP adalah metode OLS (Ordinary Least Square). Model dalam penelitian ini menggunakan fungsi Cobb-Douglas dimana nilai A pada fungsi prodoksi diartikan sebagai TFP. Pertumbuhan TFP dihitung sebagai residu, yaitu jumlah pertumbuhan output yang tersisa setelah menghitung determinan pertumbuhan yang bisa diukur (BPPT, 2012) dalam Mayashinta dan Firdaus (2013). Berikut fungsi dengan efek Teknologi:

$$
Y=A L \alpha K \beta
$$

Penelitian ini menggunakan input tenga kerja (TK), Biaya Input (IN), dan Biaya Energi (EN), sehingga persamaan menjadi :

$$
\frac{\Delta \mathrm{A}}{A}=\left(\frac{\Delta \mathrm{OUT}}{\mathrm{OUT}}\right)-a\left(\frac{\Delta \mathrm{TK}}{\mathrm{TK}}\right)-b\left(\frac{\Delta \mathrm{IN}}{\mathrm{IN}}\right)-c\left(\frac{\Delta \mathrm{EN}}{\mathrm{EN}}\right)
$$

Keterangan:

$\frac{\Delta \mathrm{A}}{A}:$ Pertumbuhan TFP $(\%)$ 
$\left(\frac{\Delta \text { OUT }}{\text { OUT }}\right)$ : Pertumbuhan output subsektor makanan, minuman, dan tembakau (\%) $\left(\frac{\Delta \mathrm{TK}}{T K}\right)$ : Pertumbuhan tenaga kerja subsektor makanan, minuman, dan tembakau (\%) $\left(\frac{\Delta \mathrm{IN}}{I N}\right)$ : Pertumbuhan biaya investasi subsektor makanan, minuman, dan tembakau (\%) $\left(\frac{\Delta \mathrm{EN}}{E N}\right)$ : Pertumbuhan energi yang digunakan subsektor agroindustri makanan, minuman, dan tembakau (\%)

Total Factor Productivity (TFP) dapat diartikan sebagai sekumpulan dari seluruh faktor kualitas menggunakan sumberdaya yang ada secara optimal untuk menghasilkan lebih banyak output dari tiap unti input, TFP dapat dianggap sabagai suatu ukuran peningkatan efisiensi dari produksi dan progress teknologi untuk jangka panjang. Laju progress teknologi dihitung untuk memperlihatkan bahwa dalam jangka panjang teknologi tidak bernilai konstan. Langkah awal yang dilakukan sebelum menghitung TFP yang dilambangkan dengan $\Delta \mathrm{A} / \mathrm{A}$ adalah meregresikan jumlah Tenaga Kerja (TK), Biaya Input (IN), dan Biaya Energy (EN) sebagai faktor-faktor produksi dari agroindustri makanan dan minuman. Langkah selanjutnya adalah menghitung pertumbuhan per tahun faktor produksi TK, IN, EN, dan pertumbuhan OUT (output). Setelah diperoleh nilai pertumbuhan faktor produksi, maka dengan pengalian koefisien ragreasi untuk setiap faktor produksi maka diperoleh nilai TFP. Nilai TFP negatif menunjukkan bahwa efisiensi produksi atau penguasaan teknologi pada industry berbasis sektor pertanian masih lemah (Mayashinta dan Firdaus, 2013).

\section{HASIL DAN PEMBAHASAN}

Hasil analisis statistik pengaruh variable bebas Tenaga Kerja (LOGTK), Biaya Input (LOGIN), dan Energi yang digunakan (LOGEN) dengan variable tak bebas Output (LOGOUT) subsektor makanan, minuman, dan tembakau Provinsi Jawa Barat menujukkan bahwa variable-variabel tersebut secara bersama-sama berpengaruh sangat nyata dengan nilai $\mathrm{F}$ hitung 811.346 dan nilai signifikansi 0,000. Hasil analisis juga menunjukkan bahwa nilai keofisien detrminasi $\left(\mathrm{R}^{2}\right)$ sebesar 0,998 menunjukkan bahwa 99,8 persen nilai output subsektor makanan, minuman, dan tembakau Provinsi Jawa Barat 
dipengaruhi oleh variable Tenaga Kerja, Biaya Input, dan Energi yang digunakan, dan hanya 0,2 persen dipengaruhi oleh factor lain.

Hasil analisis uji-t menunjukkan bahwa varibel biaya input subsektor makanan, minuman, dan tembakau berpengaruh sangat nyata terhadap output subsektor makanan, minuman, dan tembakau Provinsi Jawa Barat dengan nilai signifikasni 0,02. Varibel Energi yang digunakan subsektor makanan, minuman, dan tembakau berpengaruh nyata terhadap Output subsektor makanan, minuman, dan tembakau Provinsi Jawa Barat dengan signifikasni 0,09, sedangkan varibel Tenaga Kerja subsektor makanan, minuman, dan tembakau tidak berpengaruh nyata terhadap Output subsektor makanan, minuman, dan tembakau Provinsi Jawa Barat dengan signifikasni 0,826. Hasil analisis menunjukkan estimasi koefisien regresi masing-masing variable tidak bebas (dependen) persamaan Cobb-Douglas ditunjukkan pada Tabel 2.

Tabel 2. Hasil Estimasi Regresi Fungsi Produksi Cobb-Douglas untuk Perhitungan Koefisien

TFP Subsektor Makanan, Minuman, dan Tembakau Provinsi Jawa barat

\begin{tabular}{lllll}
\hline \multicolumn{1}{c}{ Varibel } & Koefisien & T-hitung & Probabilitas & Keterangan \\
\hline Constant & 0,922 & 2,292 & 0,062 & \\
LOGTK (Tenaga Kerja) & $-0,02$ & $-0,230$ & 0,826 & Tidak nyata \\
LOGIN (Biaya Input) & 2,576 & 3,316 & 0,020 & Sangat nyata \\
LOGEN (Energi) & $-1,682$ & $-2,020$ & 0,090 & Nyata \\
\hline
\end{tabular}

Variabel tak bebas (dependen): LOGOUT

Analisis TFP subsektor makanan, minuman, dan tembakau Provinsi Jawa Barat dilakukan melalui penelaahan pertumbuhan input produksi subsektor makanan, minuman, dan tembakau selama peiode 2001-2013 seperti ditunjukkan oleh Tabel 3.

Tabel 3. Data Pertumbuhan Output, Tenaga Kerja, Biaya Input, dan Energi yang Digunakan

Subsektor Makanan, Minuman, dan Tembakau Provinsi Jawa Barat (\%)

\begin{tabular}{|c|c|c|c|c|}
\hline Tahun & Output & Tenaga Kerja & Biaya Input & Energi \\
\hline 2001 & - & - & - & - \\
\hline 2002 & 19,912 & $-8,104$ & 18,589 & 30,870 \\
\hline 2003 & 9,672 & 5,142 & 14,131 & 5,000 \\
\hline 2004 & 8,230 & $-3,882$ & 12,815 & 20,286 \\
\hline
\end{tabular}

Diterbitkan oleh: 


$\begin{array}{rrrrr}2005 & 1,467 & -4,599 & -6,343 & 6,789 \\ 2006 & 27,382 & 38,630 & 29,553 & 27,775 \\ 2007 & 15,506 & -18,353 & 16,381 & 32,835 \\ 2008 & 20,986 & -9,694 & 27,000 & 1,260 \\ 2009 & 7,499 & -1,938 & 5,069 & -7,393 \\ 2010 & 10,749 & 9,464 & 5,519 & 26,112\end{array}$

Sumber: Jawa Barat dalam Angka 2004, 2007, 20012, dan 2013 (diolah)

Selanjutnya pertumbuhan setiap input subsektor agroindustri Makanan dan Minuman, yaitu tenaga kerja (TK), biaya input (IN), dan biaya energy (EN) dikalikan dengan koefisien regresi yang teelahan diperoleh dari hasil analisis statistic. Nilai TFP subsektor makanan, minuman, dan tembakauProvinsi Jawa Barat setiap tahunnya diperoleh dari selisih antara nillai pertumbuhan otput dikurangi dengan hasil kali pertumbuhan tenaga kerja dengan koefisien regresinya, dikurangi dengan hasil kali pertumbuhan biaya input dengan koefisien regresinya, dan dikurangi deng hasil kali pertumbuhan biaya energi dengan koefisien regresinya. Hasil perhitungan TFP tersebut dapat dilihat pada Tabel 4.

Tabel 4. Data Pertumbuhan TFP Subsektor Makanan, Minuman, dan Tembakau Provinsi Jawa Barat (\%)

\begin{tabular}{|c|c|c|c|c|c|}
\hline Tahun & Output & $\begin{array}{l}\text { Tenaga Kerja } \\
(-0,20)^{*}\end{array}$ & $\begin{array}{l}\text { Biaya Input } \\
(2,576)^{*}\end{array}$ & Energi $(-1682)^{*}$ & TFP \\
\hline 2001 & - & - & - & - & - \\
\hline 2002 & 19,912 & 0,162 & 51,231 & $-51,923$ & 20,442 \\
\hline 2003 & 9,672 & $-0,103$ & 38,944 & $-8,411$ & $-20,759$ \\
\hline 2004 & 8,230 & 0,078 & 35,318 & -34.122 & 6,955 \\
\hline 2005 & 1,467 & 0,092 & $-17,481$ & $-11,418$ & 30,275 \\
\hline 2006 & 27,382 & $-0,773$ & 81,449 & $-46,718$ & $-6,576$ \\
\hline 2007 & 15,506 & 0,367 & 45,147 & $-55,229$ & 25,221 \\
\hline 2008 & 20,986 & 0,194 & 74,411 & $-2,119$ & $-51,500$ \\
\hline 2009 & 7,499 & 0,039 & 13,970 & 12,436 & $-18,946$ \\
\hline 2010 & 10,749 & $-0,189$ & 15.211 & $-43,920$ & 39,648 \\
\hline
\end{tabular}

Rata rata TPF Subsektor makanan, minuman, dan Tembakau Jawa Barat 2000-2010 2,751 Sumber: Hasil perhitungan

*) data dalam kurung adalah koefisien regresi

Data dalam Tabel 4 menunjukkan perubahan nilai TFP selama periode 2002-2013. Hal ini merupakan akumulasi perubahan petumbuhan input yang berbeda beda selama 
periode tersebut. Secara keseluruhan, selama periode tersebut, nilai TFP rata-rata Subsektor makanan, minuman, dan tembakauJawa Barat adalah 2,751 yang menunjukkan produktivitas dan efisiensi yang tinggi dari subsektor tersebut. Hal ini juga menunjukkan subsektor makanan, minuman, dan tembakau merupakan subsektor unggulan Provinsi Jawa barat.

Sektor unggulan ini berperan penting dalam peningkatan PDRB provinsi Jawa Barat dan tidak tertutup kemungikan akan menyamai kontribusi PDRB subsektor industri tekstil, barang kulit, dan alas kaki yang masih dominsn seperti ditunjukkan pada Lampiran 1. Ekpansi industri makanan dan minuman Provinsi Jawa Barat ke berbagai daerah melalui distribusi manual maupun dalam jaringan, merupakan opsi yang tepat dalam meningkatkan produksi dan produktivitas dengan dukungan input melalui distribusi melalui distribusi produksi yang memadai.

Tetapi adanya fluktuasi yang besar dari nilai TFP selama periode tersebut menunjukkan bahwa proses produksi subskctor ini sangat tidak stabil, yang diduga berkaitan dengan penyediaan input tenaga kerja yang sangat berfluktuasi yang juga ditunjukkan oleh pertumbuhan tahunan yang fluktuatif dari tenaga kerja subsektor agroindustri makanan, minuman dan tembakau, yaitu tahun 2002, 2004, 2005, 2007, 2008, dan 2009, demikian pula berkaitan dengan pertumbuhan penggunaan energi yang negatif seperti ditunjukkan pada Tabel 4. Tenaga kerja, biaya input, dan energi merupakan input produksi utama yang harus tersedia dalam jumlah memadai sebagimana dinyatakan Sukirno (2002) bahwa Output produksi merupakan fungsi dari tenaga kerja dan modal (biaya input dan energi). Tenaga kerja, biaya input, dan energi membutuhkan ketersediaan yang meningkat terus menerus dari tahun ketahun. Hal ini untuk menjamin peningkatan produktivitas yang bermuara pada peningkatan kontribusi subsektor makanan, minuman, dan tembakau terhadap PDRB Provinsi Jawa Barat.

\section{SIMPULAN}

Nilai TFP rata-rata subsektor makanan, minuman, dan tembakauProvinsi Jawa Barat selama periode 2002-2013 adalah 2,751, yang menunjukkan produktivitas dan 
efieiensi yang tinggi dari subsector tersebut. Tetapi selama periode tersebut terjadi fluktuasi yang sangat besar yang diduga terutama disebabkan oleh pertumbuhan tenaga kerja yang negative selama yaitu tahun 2002, 2004, 2005, 2007, 2008, dan 2009. Oleh karena itu disarankan agar tetap dipertahankan pertumbuhan tenaga kerja, energi, dan biaya input yang positif dari subsektor makanan, minuman, dan tembakau Provinsi Jawa Barat selama periode 2002-2013.

\section{DAFTAR PUSTAKA}

Asian Produkivity Organization. (2004). Laporan Data Asian Productivity Organization (APO).

BPS Provinsi Jawa Barat. (2004). Jawa Barat dalam Angka 2004/205, diakses dari https://jabar.bps.go.id/publication/download.html?nrbvfeve=ZDA2MjlhZTEWMTcyMTc3YTI kNGI5OTdk\&xzmn=aHROcHM6Ly9qYWJhci5icHMuZ28uaWQvcHVibGljYXRpb24vMjAwOS8w MS8wMS9kMDYyOWFIMTAxNzIxNzdhOWQOYjk5N2QvamF3YS1iYXJhdC1kYWxhbS1hbmdrY SOyMDA3Lmh0bWw\%3D\&twoadfnoarfeauf=MjAxOS0xMC0zMSAxNTozOTo00Q\%3D\%3D

BPS Provinsi Jawa Barat. (2007). Jawa Barat dalam Angka 2007. Diakses deri https://jabar.bps.go.id/publication/download.html?nrbvfeve=NzRmMzQOMTUxYjlzYWJhM TQwMmExNTIm\&xzmn=aHROcHM6Ly9qYWJhci5icHMuZ28uaWQvcHVibGljYXRpb24vMjAx My8wMS8xNy83NGYzNDQXNTFiMjNhYmExNDAyYTE1OWYvamF3YS1iYXJhdC1kYWxhbS1hb mdrYSOyMDEyLmhObWw\%3D\&twoadfnoarfeauf=MjAxOSOxMC0zMSAxNTo0NDoyNw\%3D\% $3 \mathrm{D}$

BPS Provinsi Jawa Barat. (2012). Jawa Barat dalam Angka 2012diakses dari https://jabar.bps.go.id/publication/download.html?nrbvfeve=NzRmMzQOMTUxYjlzYWJhM TQwMmExNTIm\&xzmn=aHROcHM6Ly9qYWJhci5icHMuZ28uaWQvcHVibGljYXRpb24vMjAx My8wMS8xNy83NGYzNDQxNTFiMjNhYmExNDAyYTE1OWYvamF3YS1iYXJhdC1kYWxhbS1hb mdrYSOyMDEyLmhObWw\%3D\&twoadfnoarfeauf=MjAxOSOxMCOzMSAxNTo0NDoyNw\%3D\% $3 \mathrm{D}$

BPS. (2013). Jawa Barat dalam Angka 2013 diakses dari https://jabar.bps.go.id/publication/download.html?nrbvfeve=NjA4ZGMyZjVkMDY4MGNhM TY3YzZIMzBh\&xzmn=aHROcHM6Ly9qYWJhci5icHMuZ28uaWQvcHVibGljYXRpb24vMjAxMy8 xMS8wOC82MDhkYzJmNWQwNjgwY2ExNjdjNmUzMGEvamF3YS1iYXJhdC1kYWxhbS1hbmd rYSOyMDEzLmhObWw\%3D\&twoadfnoarfeauf=MjAxOSOxMCOzMSAxNToONTozOQ\%3D\%3D 
Depnakertrans, 2003, Pengukuran Dan Analisis Produktivitas Total Faktor Produktivitas (PTF) Sektor Industri Pengolahaan.

Jabir A, Surendra P. S, and E. Ekanemc. Efficiency and Productivity Changes in the Indian Food Processing Industry: Determinants and Policy Implications. International Food and Agribusiness Management Review Volume 12, Issue 1, 2009

Juarno, O, Oktaviani, R, Fauzi, A \& Nuryartono, N. (2011). Kinerja Produktivitas Dan Faktor Yang Berpengaruh Terhadap Total Factor Productivity (TFP) Tambak Udang Indonesia. Jurnal Sosek Kp, Vol. 6 No. 2, 2011

Kijek, A, T. Kijek, A. Nowak, A. Skrzypek, \& M. C. Sklodowska. (2019). Productivity and its convergence in agriculture in new and old European Union member states. Agricultural Economics - Czech, Vol 65, 2019 pp: 01-09.

Lipsey, R and K Carlaw. (2004). Total factor productivity and the measurement of technological change. Canadian Journal of Economics, Vol. 37, No 4, 1118-1150

Mayashinta, W dan Firdaus, M. (2013). Faktor-faktor yang Mempengaruhi Total Factor Productivity Industri Pertanian Indonesia Periode 1981-20010. Jurnal Manajemen dan Agribisnis, Vol. 10, No 2

Miller, R. R dan R. E. Meiners, 1997. Teori Ekonomi Mikro Intermediate, Jakarta: PT. Raja Grafindo Persada.

Pindyck, Robers, D.1 Rubinfeld, 2001. Mikro Ekonomi Edisi Kelima Diterjemahkan oleh Tanty Tarigan, Penerbit Indeks, Jakarta.

Saikia, D. (2014).Total Factor Productivity in Agriculture: A Review of Measurement Issues in The Indian Context. Romanian Journal of Regional Science, Vol 8, No 2, Winter 2014

Shanmugan, K. \& B P Bhagirath. (2018). Total factor productivity in Indian agriculture: An exploratory analysis based on literature review. Agricultural Reviews, Vol 39, No 2, Hal 113-121

Sukirno, S. (2002). Pengantar Teori Mikro Ekonomi. Jakarta: PT Grafindo Persada. 
Lampiran 1. PDRB Jawa Barat Atas Dasar Harga Konstan Tahun 2000 (Juta Rupiah)

\begin{tabular}{|c|c|c|c|c|c|}
\hline SEKTOR/SUBSEKTOR & 2007 & 2008 & 2009 & 2010 & Rata-rata \\
\hline PERTANIAN & $35.687 .490,00$ & $36.505 .378,00$ & $41.250 .867,00$ & $42.137 .486,00$ & 38.895.305,25 \\
\hline $\begin{array}{l}\text { PERTAMBANGAN DAN } \\
\text { PENGGALIAN }\end{array}$ & $6.491 .519,00$ & $6.841 .541,00$ & 7.424.424,00 & 7.464.691,00 & 7.055.543,75 \\
\hline INDUSTRI MIGAS & $2.244 .324,00$ & $2.199 .673,00$ & $2.263 .413,00$ & $2.173 .797,00$ & $2.220 .301,75$ \\
\hline $\begin{array}{l}\text { 1) Makanan, Minuman dan } \\
\text { Tembakau }\end{array}$ & $14.263 .760,08$ & $13.802 .269,53$ & $14.593 .464,00$ & $14.388 .196,00$ & $14.261 .922,40$ \\
\hline $\begin{array}{l}\text { 2) Tekstil, Barang Kulit \& Alas } \\
\text { Kaki }\end{array}$ & $28.537 .420,28$ & $27.420 .706,28$ & 26.301.087,00 & $24.469 .503,00$ & 26.682.179,14 \\
\hline $\begin{array}{l}\text { 3) Barang Kayu \& Hasil Hutan } \\
\text { Lainnya }\end{array}$ & $1.608 .001,48$ & $1.589 .552,25$ & $1.818 .574,00$ & $1.594 .762,00$ & 1.652.722,43 \\
\hline 4) Kertas dan Barang Cetakan & $2.905 .066,03$ & $2.715 .706,70$ & $2.856 .221,00$ & $3.454 .332,00$ & 2.982.831,43 \\
\hline $\begin{array}{l}\text { 5) Pupuk, Kimia \& Barang dari } \\
\text { Karet }\end{array}$ & 13.917.168,89 & $11.561 .363,34$ & $11.666 .430,00$ & $10.411 .861,00$ & 11.889.205,81 \\
\hline INDUSTRI NON AGRO & & $74.467 .284,90$ & $71.933 .675,00$ & $78.754 .323,00$ & 75.051.760,97 \\
\hline LISTRIK, GAS, AIR & $5.750 .579,00$ & $6.025 .769,00$ & 7.039.235,00 & 7.315.960,00 & 6.532.885,75 \\
\hline KONSTRUKSI & $8.928 .178,00$ & $9.730 .820,00$ & $10.299 .411,00$ & $11.810 .047,00$ & $10.192 .114,00$ \\
\hline $\begin{array}{l}\text { PERDAGANGAN, HOTEL, } \\
\text { RESTORAN }\end{array}$ & $54.789 .912,00$ & $56.937 .923,00$ & $62.701 .714,00$ & $70.083 .413,00$ & $61.128 .240,50$ \\
\hline $\begin{array}{l}\text { PENGANKUTAN } \\
\text { DANKOMUNIKASI }\end{array}$ & $12.271 .025,00$ & $12.233 .940,00$ & $13.191 .978,00$ & $15.352 .858,00$ & $13.262 .450,25$ \\
\hline $\begin{array}{l}\text { KEUANGAN, REAL ESTATE \& } \\
\text { JASA KEUANGAN }\end{array}$ & $8.645 .553,00$ & $9.075 .520,00$ & $9.618 .612,00$ & $10.564 .691,00$ & $9.476 .094,00$ \\
\hline JASA-JASA & $18.728 .218,00$ & $19.063 .682,00$ & $19.670 .444,00$ & $21.899 .922,00$ & $19.840 .566,50$ \\
\hline Total & $214.768 .214,76$ & $290.171 .129,00$ & $302.629 .549,00$ & $321.875 .842,00$ & 282.361.183,69 \\
\hline
\end{tabular}

Sumber: jabar.bps.go.id 
Lampiran 2. Data Nilai Output, Tenaga Kerja, Biaya Input, dan Enrgi yang Digunakan Subsektor Makanan, Minuman, dan Tembakau Jawa Barat

\begin{tabular}{|r|r|r|r|r|}
\hline Tahun & Output & \multicolumn{1}{|c|}{ Tenaga Kerja } & \multicolumn{1}{c|}{ Biaya Input } & Biaya Energi \\
\hline & (Juta Rp) & (Jiwa) & \multicolumn{2}{|c|}{ (Juta Rp) } \\
\hline $2001 \mathrm{a})$ & 11.007 .868 & 95.963 & 8.017 .695 & 327.399 \\
\hline $2002 \mathrm{a})$ & 13.744 .772 & 88.769 & 10.038 .589 & 473.596 \\
\hline $2003 \mathrm{a})$ & 15.216 .512 & 93.581 & 11.514 .132 & 625.394 \\
\hline $2004 \mathrm{~b})$ & 16.581 .055 & 90.084 & 10.827 .354 & 670.941 \\
\hline $2005 \mathrm{~b})$ & 16.827 .969 & 86.123 & 15.369 .589 & 928.965 \\
\hline $2006 \mathrm{~b})$ & 23.173 .248 & 140.334 & 18.380 .577 & 1.383 .111 \\
\hline $2007 \mathrm{c})$ & 27.425 .982 & 118.572 & 25.178 .795 & 1.400 .760 \\
\hline $2008 \mathrm{c})$ & 34.710 .197 & 108.093 & 26.523 .280 & 1.304 .325 \\
\hline $2009 \mathrm{c})$ & 37.524 .106 & 106.038 & 28.072 .641 & 1.76 .5264 \\
\hline 2010d) & 117.122 & 117.122 & & \\
\hline
\end{tabular}

Keterangan a) Data dari Jawa Barat Dalam Angka Tahun 2004

b) Data dari Jawa Barat Dalam Angka Tahun 2007

c) Data dari Jawa Barat Dalam Angka Tahun 2012

d) Data dari Jawa Barat Dalam Angka Tahun 2013 
Jln. Ir. H. Juanda Km 3 Indramayu, Jawa Barat 